\title{
Controlled growth of hydroxyapatite on the surface of natural stilbite from Ethiopia: application in mitigation of fluorosis
}

\author{
Luis Gómez-Hortigüela, ${ }^{a}$ Joaquín Pérez-Pariente, ${ }^{a}$ Yonas Chebude ${ }^{b}$ \\ and Isabel Díaz ${ }^{\star a b}$
}

Received 20th November 2013 Accepted 10th January 2014

DOI: $10.1039 / c 3 r a 46866 f$

www.rsc.org/advances

\begin{abstract}
This contribution reports the preparation of a composite material based on a natural zeolite rich in calcium, stilbite, on which surface nanosized hydroxyapatite is grown under controlled conditions. Low crystallisation temperatures enable the crystallisation of nano-sized hydroxyapatite crystals, which display a very high intrinsic capacity (based on weight of hydroxyapatite) of fluoride removal. The low cost and easy accessibility of the materials employed for its preparation, as well as the simplicity of the synthesis procedure, make these materials suitable candidates for their use in fluoride removal from drinking water.
\end{abstract}

\section{Introduction}

Fluoride $\left(\mathrm{F}^{-}\right)$is one of the most abundant anions in groundwater all over the world. Fluoride is widespread in rocks and soils of the Earth's crust. The occurrence of fluoride in groundwater comes from the partial dissolution of fluoridecontaining rocks, with the most important compounds being fluorite $\left(\mathrm{CaF}_{2}\right)$, cryolite $\left(\mathrm{Na}_{3} \mathrm{AlF}_{6}\right)$ and fluoroapatite $\left(\mathrm{Ca}_{5}\left(\mathrm{PO}_{4}\right)_{3} \mathrm{~F}\right)$. The presence of fluoride in drinking water can be beneficial or harmful to human health depending on the concentration. At concentrations in water ranging between 1.0 and $1.5 \mathrm{mg} \mathrm{L}^{-1}$, fluoride is beneficial, especially for children, for the calcification of the dental enamel. In contrast, a too high ingestion of fluoride can lead to dental and/or skeletal fluorosis. ${ }^{1}$ The World Health Organisation (WHO) predicted in 1984 that more than 260 million people consume water with a concentration of fluoride higher than $1.0 \mathrm{mg} \mathrm{L}{ }^{-1}{ }^{2}$ Hence, the development of technologies, preferably low-cost and environmentally friendly, capable of reducing the fluoride concentration below the limit established by WHO $\left(1.5 \mathrm{mg} \mathrm{L}^{-1}\right)$ represents nowadays a worldwide crucial target.

Too high concentrations of fluoride frequently occur in groundwater, where the contact time between the water and fluorine-containing minerals is high, especially in North America, Africa, particularly in the Rift Valley area, and in Asia. In more than 20 countries fluorosis has become an endemic problem, the worst situation occurring in China, India, Sri Lanka and the countries of the Rift Valley, in particular Kenya, Tanzania and Ethiopia.

${ }^{a}$ Instituto de Catálisis y Petroleoquímica, CSIC, c/Marie Curie 2, 28049 Madrid, Spain. E-mail: idiaz@icp.csic.es; Fax: +34 915854760; Tel: +34915854785

${ }^{b}$ Chemistry Department, Addis Ababa University, Addis Ababa, Ethiopia
Existing defluoridation technologies include precipitationcoagulation, membrane-based processes, ion-exchange methods, and adsorption methods. ${ }^{3}$ The fundamental issue for the implementation of adsorption methods is the proper choice of the material to be used as an adsorbent. A large variety of materials have been studied, including impregnated and activated alumina, rare earth oxides, clays and other soil materials, impregnated silica, carbon materials, calcium-based materials, bone char, zeolites and natural biopolymers. ${ }^{4}$ However, when the concentration of fluoride in water is reduced to actual concentrations present in groundwaters, generally below $10 \mathrm{mg} \mathrm{L} \mathrm{L}^{-1}$, many of these materials partially lose their defluoridation capacity, and very often they are not able to reduce the concentration below the WHO limit.

Following human metabolism, whereby fluoride is removed from water and taken up by our teeth and bones through the hydroxyapatite component, one of the most widely tested adsorbents has traditionally been hydroxyapatite (HAp, $\left.\mathrm{Ca}_{5}\left(\mathrm{PO}_{4}\right)_{3} \mathrm{OH}\right) .^{5-12}$ The main mechanism of fluoride removal by HAp occurs through the isomorphic substitution of hydroxide by fluoride in the crystalline network, owing to their same electric charge and similar ionic radii, together with the higher stability of fluoroapatite; this is the same mechanism whereby fluoride is taken up by the human body, with the consequent beneficial or harmful effects. Assuming such mechanism, the maximum theoretical fluoride uptake capacity of HAp would be $37.8 \mathrm{mg}$ of $\mathrm{F}^{-}$per $\mathrm{g}$ of HAp. Nevertheless, hydroxide anions in the crystalline network of HAp are located within 6-membered ring channels. Diffusion along these channels and the subsequent isomorphic substitution by fluoride is partially restricted, what explains the higher intrinsic capacity of fluoride removal found for smaller crystals. ${ }^{13-15}$ Hence, a reduction of the particle size of HAp to the nano-sized scale should bring a notable improvement of fluoride removal capacity. Indeed, high 
removal capacities have been found for nanohydroxyapatites (nHAp), showing capacities between 1 and $3 \mathrm{mg}$ of $\mathrm{F}^{-}$per $\mathrm{g}$ of HAp. ${ }^{13}$ In this direction, and aiming to avoid pressure drops during filtration due to the nanosized scale of HAp, Sundaram et al. prepared composite materials of HAp and biopolymers such as chitosan or chitin that can be prepared in any desired shape allowing reasonable removal capacities. ${ }^{16}$

Zeolites represent a class of materials that have all the required properties to be used as adsorbents. ${ }^{17}$ Indeed, they are used as cation-exchangers world-wide, even as adsorbents in water and wastewater treatments. As previously mentioned, mitigation of fluorosis by adequate simple defluoridation technologies is a crucial target in Ethiopia. In this context, zeolites are a vast natural resource in this country that remains unexploited. It is worth noting that both zeolites and fluoridecontaining groundwaters share a volcanic origin, and therefore they are usually geographically associated. Previous studies showed abundant resources of mordenite and clinoptilolite near Adama (Nazret) ${ }^{18}$ and phillipsite and also clinoptilolite in the Hawassa area.$^{19}$ In our attempt to survey the deposits in the northern region of the country, several samples have been studied and at least one highly pure large deposit of stilbite has been identified..$^{20}$ In the present manuscript we describe the preparation of high-performing nHAp for fluoride removal, using a natural zeolite, stilbite, as a source of calcium ions and as a controlling agent for the growth of HAp, thus producing a composite stilbite-nHAp material. ${ }^{21}$ This natural stilbite releases the $\mathrm{Ca}^{2+}$ present within its cavities by ion exchange in a very slow and controlled way. This is due to the particular topology of this framework composed by channels of relatively small sizes, which make diffusion of the $\mathrm{Ca}^{2+}$ cations towards the outer surface of the crystal difficult. ${ }^{22} \mathrm{Ca}^{2+}$ ions are first ion-exchanged by $\mathrm{NH}_{4}{ }^{+}$, thus being released to the solution which, in the presence of $\mathrm{PO}_{4}{ }^{3-}$ and at an adequate $\mathrm{pH}$, leads to a precipitation of HAp on the zeolite surface with very small particle sizes. By carefully controlling the Ca- $\mathrm{NH}_{4}$ exchange through variations of temperature and time, we manage to produce decreasingly smaller nHAp crystals with increasingly higher $\mathrm{F}$ uptake capacities. This adsorbent has proven to be efficient in elimination of $\mathrm{F}$ from waters, leading to what we believe is a low-cost and non-energy intensive technology.

There is a precedent in the literature of HAp crystallisation on the surface of a synthetic zeolite, zeolite A (LTA) ${ }^{23}$ The main application of this synthetic procedure of HAp on the zeolite surface was to achieve a total coverage of the zeolite surface with the aim of trapping radioactive ions or other contaminants within the zeolite void volume, preventing their release. ${ }^{24}$ The reported method yields large HAp crystals on the zeolite surface. In our work, room temperature and a relatively short period of time showed the optimum HAp particle size with the highest $\mathrm{F}^{-}$removal capacity. This low energy demanding process together with the use of a natural zeolite, stilbite, as a source of one of the reagents yields a promising technology that can be easily implemented in areas with large presence of fluorosis and energy supply problems, such as the rural Ethiopian Rift Valley.

\section{Results and discussion}

The natural zeolite stilbite mineral coming from Ethiopia, which has a STI framework type ${ }^{25}$ has a remarkably high content on $\mathrm{Ca}^{2+}$ of 5.23 weight\% (Table 1).

The X-ray diffraction pattern (Fig. 1-bottom) indicates that it is a highly pure stilbite mineral. The growth of HAp is carried out through a simultaneous release of $\mathrm{Ca}^{2+}$ to the solution media by ion-exchange with $\mathrm{NH}_{4}{ }^{+}$(XRD showed that this treatment did not distort the stilbite framework structure, Fig. 1-grey line) followed by in situ crystallisation on the zeolite surface in the presence of $\mathrm{PO}_{4}{ }^{3-}$ at a pH of 9.0. $2.00 \mathrm{~g}$ of sieved stilbite zeolite (with particle size between 0.074 and $0.125 \mathrm{~mm}$ ) are added to $30 \mathrm{~mL}$ of $1 \mathrm{M}$ solution of $\left(\mathrm{NH}_{4}\right)_{2} \mathrm{HPO}_{4}$ and stirred for 10 minutes. A $25 \%$ solution of $\mathrm{NH}_{3}$ is added to adjust the $\mathrm{pH}$ to 9.0. Crystallisation of nHAp is then undertaken at temperatures ranging from 150 to $25^{\circ} \mathrm{C}$, for periods of time between 2 and 66 hours. The final product is filtered off and washed with abundant distilled water. The diffractogram of the composite obtained at $150{ }^{\circ} \mathrm{C}$ (Fig. 1-top) indicates that the STI framework resists the hydrothermal treatment; besides, additional peaks of weak intensity are observed at $2 \theta$ angles of $26,32,34$ and 40 degrees, that are assigned to the formation of HAp crystals (Fig. 1-inset). When the crystallisation takes place at $25^{\circ} \mathrm{C}$, such HAp peaks are not appreciated in the XRD patterns of the composite samples, most probably due to the lower concentration of HAp in the solid and the overlapping with the zeolite diffractions, and possibly to its small crystal size.

Table 1 Composition of the natural zeolite stilbite (measured by ICP, in weight\%)

\begin{tabular}{llllll}
\hline $\mathrm{Al}$ & $\mathrm{B}$ & $\mathrm{Ca}$ & $\mathrm{Mg}$ & $\mathrm{Fe}$ & $\mathrm{K}$ \\
8.67 & 0.81 & 5.23 & 0.16 & 0.43 & 0.10 \\
$\mathrm{Li}$ & $\mathrm{Mn}$ & $\mathrm{Na}$ & $\mathrm{Nb}$ & $\mathrm{Si}$ & $\mathrm{Ti}$ \\
0.51 & 0.01 & 0.80 & 0.01 & 29.50 & 0.11
\end{tabular}

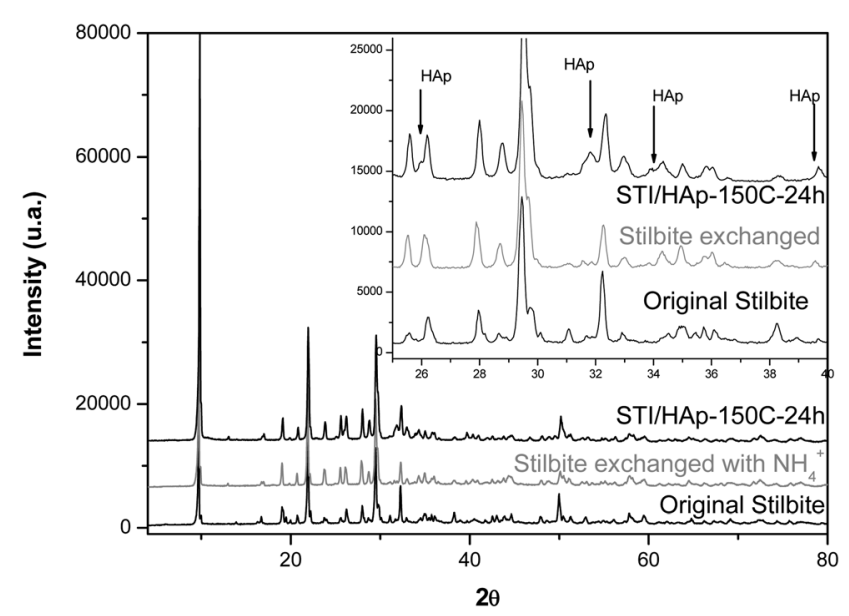

Fig. 1 XRD patterns of original natural stilbite (bottom), after exchange with $\mathrm{NH}_{4}{ }^{+}$(middle in grey) (exchange conditions: $1 \mathrm{M} \mathrm{NH}_{4} \mathrm{Cl}$ at $90{ }^{\circ} \mathrm{C}$ for $16 \mathrm{~h}$ ) and STI/HAp composite obtained after 24 hours of crystallisation at $150{ }^{\circ} \mathrm{C}$ (top). Black arrows indicate peaks tentatively assigned to HAp crystals. 
${ }^{31} \mathrm{P}$ MAS-NMR was used to confirm the presence of HAp in these composites. Fig. 2 shows the same signal observed at 2.7 ppm in both cases, characteristic of $\mathrm{P}$ in HAp. ${ }^{26}$ Interestingly, in the case of the composite obtained at $25{ }^{\circ} \mathrm{C}$, the band is broader and shows a shoulder at around $0 \mathrm{ppm}$, being both features related to the nanometric nature of $\mathrm{HAp},{ }^{27}$ which suggest a smaller particle size of the HAp grown at lower temperatures.

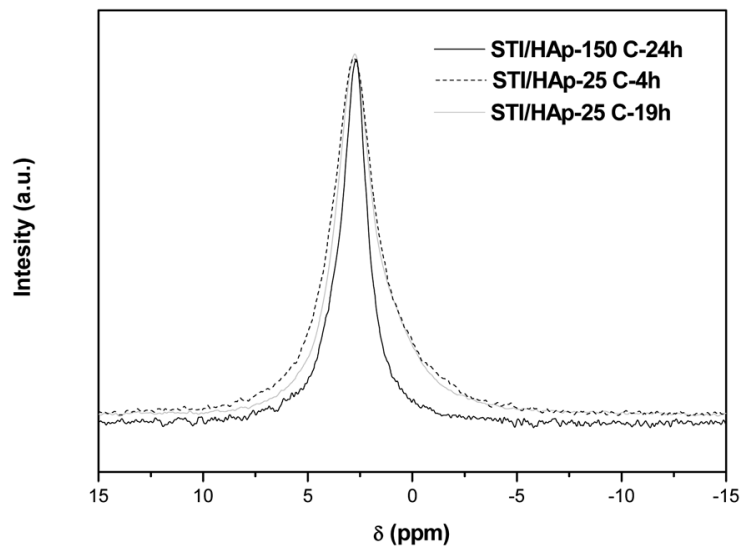

Fig. $2{ }^{31} \mathrm{P}$ MAS NMR of STI/HAp composites prepared at $150^{\circ} \mathrm{C}$ (for 24 hours) (black line), at $25^{\circ} \mathrm{C}$ for 4 hours (grey line) and at $25^{\circ} \mathrm{C}$ for 19 hours (dashed line).
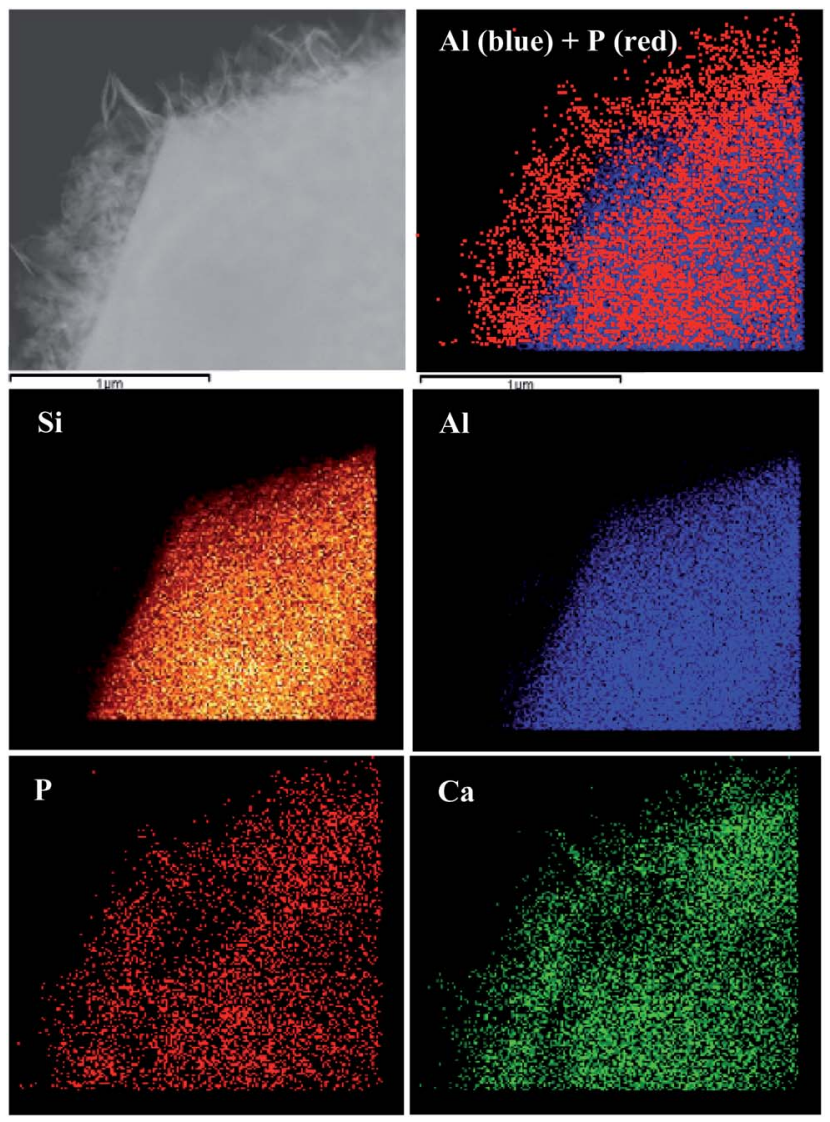

Fig. 3 TEM-EDX of STI/HAp composite prepared at $25^{\circ} \mathrm{C}$ for 19 hours.
TEM-EDX mapping observations (Fig. 3) clearly show the crystallisation of HAp on the external surface of the zeolite, distinguishable by its main constituent element $\mathrm{P}$ (red) not present in the zeolite, attached to the surface of the zeolite crystals, whose identifying element is $\mathrm{Al}$ (blue) or $\mathrm{Si}$ (orange). $\mathrm{Ca}$ ions (green) are present both in HAp and in the zeolite.

The amount of HAp crystallised was determined from the P wt \% content measured by ICP (eqn (1)); Fig. 4 shows the percentage of HAp crystallised (relative to the total theoretical

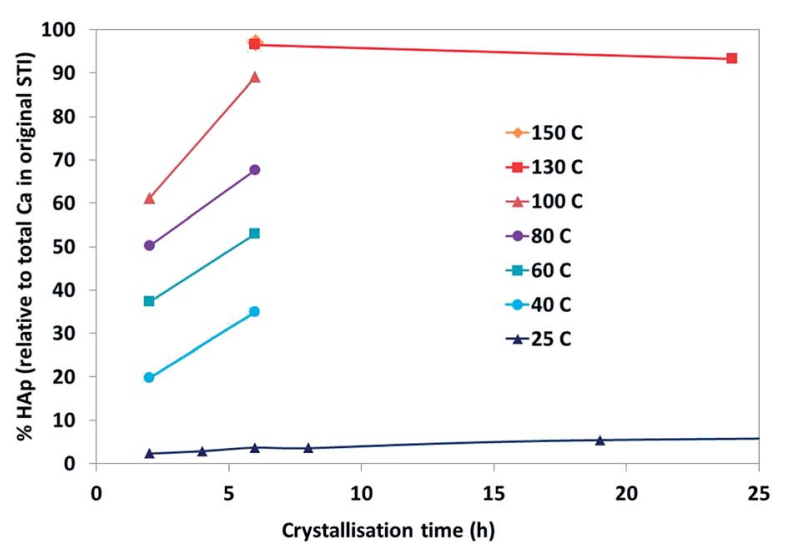

Fig. 4 Percentage of HAp crystallisation (relative to theoretical total based on the $\mathrm{Ca}$ content) as a function of crystallisation temperature and time.

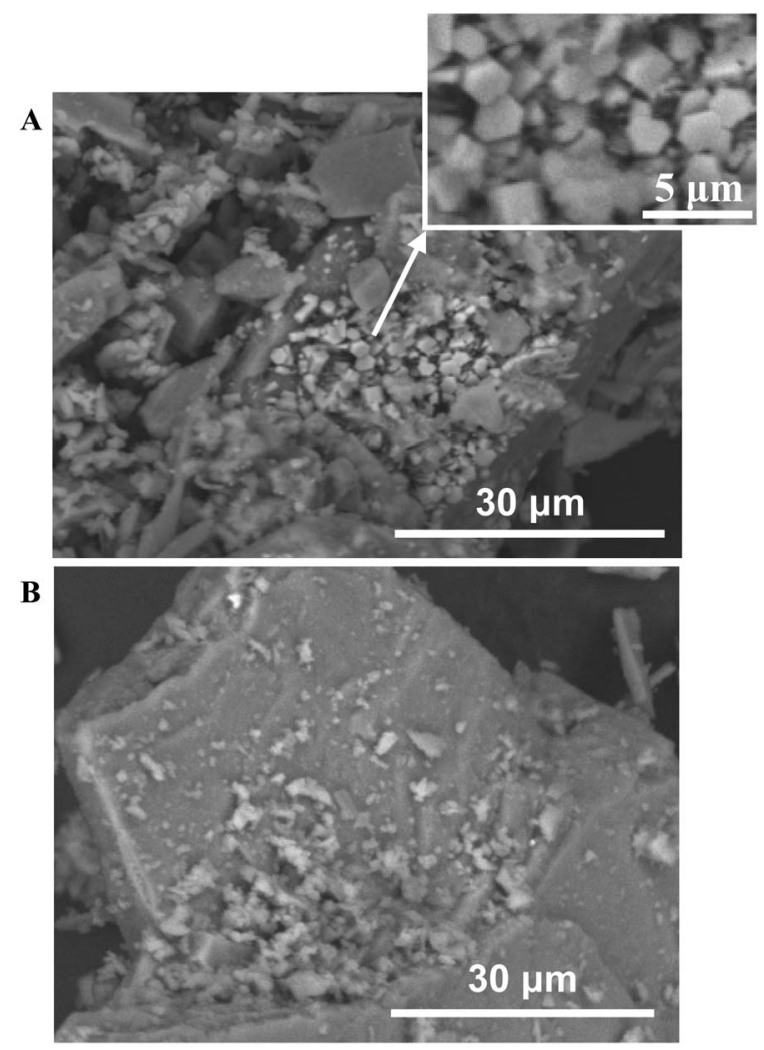

Fig. 5 SEM micrographs of STI/HAp composites crystallised at $150{ }^{\circ} \mathrm{C}$ for 24 hours (A) or $25^{\circ} \mathrm{C}$ for 6 hours (B). 
amount if all the Ca present crystallised as HAp) as a function of the crystallisation time at different temperatures (displayed in different colors). A notable increase of the HAp crystallisation is observed when increasing the temperature and the time; most of all the $\mathrm{Ca}$ from the zeolite is exchanged and crystallises as HAp at $130-150{ }^{\circ} \mathrm{C}$. Indeed, HAp crystals are clearly observed by SEM as hexagonal needles (Fig. 5A). When the crystallisation temperature decreases, both the amount (Fig. 4) and the size of HAp crystals are notably reduced; in this case, the crystal morphology of HAp is not distinguished by SEM (Fig. 5B). At the low temperature of $25{ }^{\circ} \mathrm{C}$, where $\mathrm{Ca}^{2+} / \mathrm{NH}_{4}{ }^{+}$exchange and consequent HAp crystallisation occurs (as evidenced by ${ }^{31} \mathrm{P}$ NMR) but to a smaller extent, the amount of HAp crystallised can be controlled by adjusting the synthesis time (Fig. 4).

The behaviour of these STI/HAp composites has been analysed on a demanding process of removal of fluoride from water with initial fluoride concentrations of about $5 \mathrm{mg} \mathrm{\textrm {L } ^ { - 1 }}$ (at autogeneous $\mathrm{pH}$ of $8-8.5$ ). A clear relationship between the amount of HAp crystallised and its associated $\mathrm{F}^{-}$removal intrinsic capacity (calculated relative to the HAp mass in the composite, following eqn (2)) is found (Fig. 6A): the higher the amount of HAp crystallised, the lower its associated
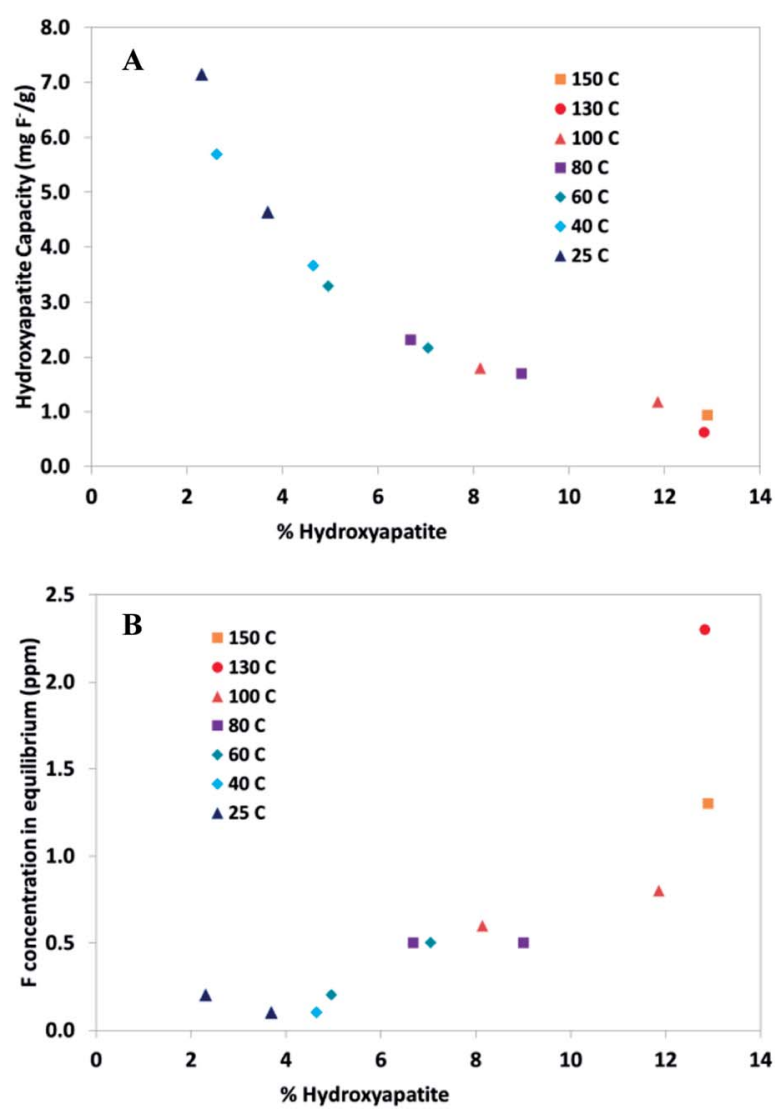

Fig. 6 (A) Intrinsic HAp capacity (in $\mathrm{mg}$ of $\mathrm{F}^{-}$per gram of HAp) as a function of the amount of HAp (in wt percentage), using a dose of $25 \mathrm{~g} \mathrm{~L}^{-1}$ of the composite; (B) fluoride concentration in equilibrium (in $\mathrm{mg} \mathrm{L}^{-1}$ ) as a function of the amount of $\mathrm{HAp}$ (in percentage with respect to the theoretical total), using a dose of $25 \mathrm{~g} \mathrm{~L}^{-1}$ of the composite; the initial fluoride concentration was $4.3 \mathrm{mg} \mathrm{L}^{-1}$. defluoridation capacity. Such behaviour is due to the smaller crystal size of HAp crystallised at lower temperatures, as suggested by ${ }^{31} \mathrm{P}$ NMR and SEM. STI/HAp composites obtained at higher temperatures reduced less efficiently the fluoride concentration, despite having a larger amount of the fluorideremoval active HAp phase (Fig. 6B). This represents a clear evidence that nHAp of decreasing crystal size is more efficient for $\mathrm{F}^{-}$exchange, possibly due to a less restricted diffusion (shorter diffusion pathway) through the 6-ring channels. In fact, longer crystallisation times (at $25^{\circ} \mathrm{C}$ ) leads to more HAp but of reduced intrinsic capacity (Fig. 7). Therefore, the HAp crystal size, and as a consequence the fluoride removal capacity, of these composites can be easily controlled by means of adjusting the crystallisation temperature and time.

Fig. 8 shows the defluoridation of a solution with $5.0 \mathrm{mg}$ $\mathrm{L}^{-1}$ of fluoride initial concentration as a function of the HAp dose, and the associated intrinsic HAp defluoridation capacity. The limit imposed by the WHO of $1.5 \mathrm{mg} \mathrm{L}^{-1}$ is reached with a dose of $0.5 \mathrm{~g}$ of HAp per litre. It should be noted

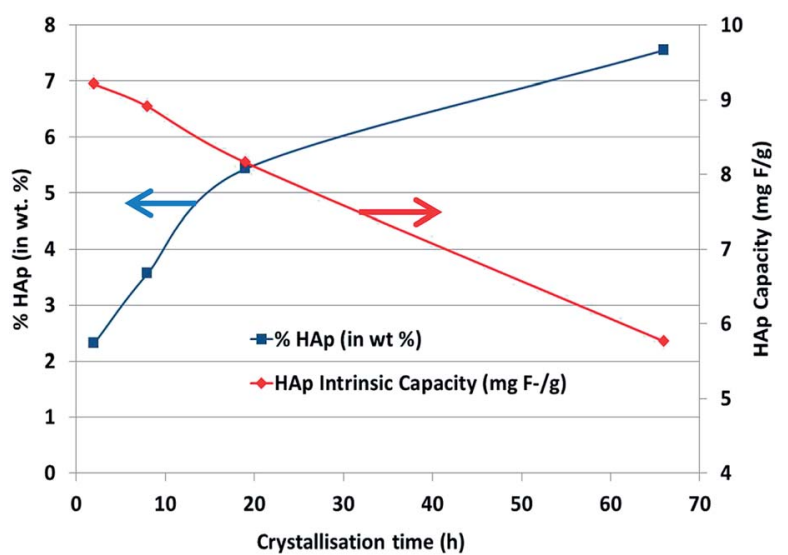

Fig. 7 Percentage of HAp crystallised (left axis, in blue) and intrinsic HAp fluoride removal capacity (right axis, in red) as a function of the crystallisation time (at $25^{\circ} \mathrm{C}$ ).

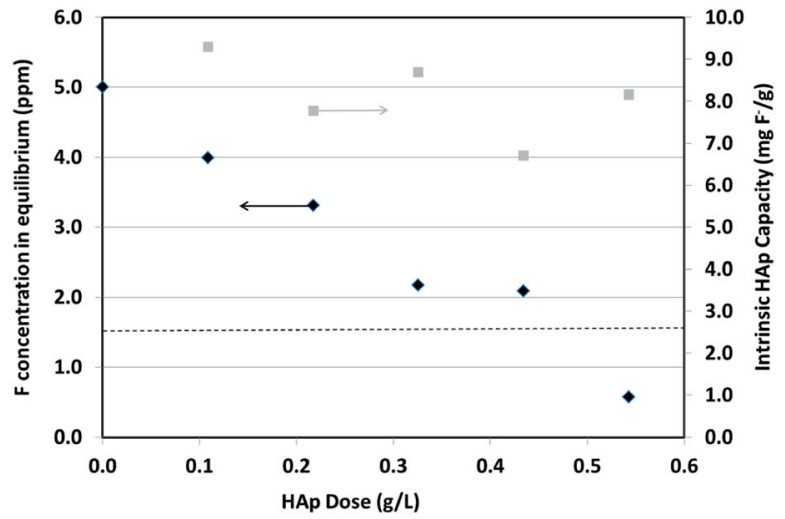

Fig. 8 Concentration of fluoride in equilibrium (in $\mathrm{mg} \mathrm{L}^{-1}$ ) (left axis, black dots) and intrinsic fluoride removal HAp capacity (in $\mathrm{mg}$ of $\mathrm{F}^{-}$per $\mathrm{g}$ of HAp) (right axis, grey dots) as a function of the HAp dose; initial F concentration: $5 \mathrm{mg} \mathrm{L}^{-1}$. 
that the intrinsic defluoridation capacity of HAp remains constant at very high values between 7 and $9 \mathrm{mg}$ of fluoride per $\mathrm{g}$ of HAp in the demanding $\mathrm{F}^{-}$-removal process of adsorbing $\mathrm{F}^{-}$in such low concentrations $\left(5 \mathrm{mg} \mathrm{L}^{-1}\right)$. To our knowledge, such intrinsic HAp defluoridation capacities are the highest ones found so far for reducing the $\mathrm{F}^{-}$concentrations from such low initial concentrations $\left(\sim 5 \mathrm{mg} \mathrm{L}^{-1}\right)$. Besides, the presence of the zeolite as a support for a high capacity material such as the nanohydroxyapatite grown under the conditions described in this work decreases the engineering and toxicity problems related to the use of small particle sizes. Finally, a series of preliminary experiments has shown that this type of adsorbent can be regenerated under a basic treatment to recover up to $90 \%$ of the initial defluoridation ability, and therefore the fluoride removal is reversible, an essential issue in these adsorbents.

\section{Experimental}

The STI/HAp composites were characterized by different physicochemical techniques. Powder X-ray diffraction (XRD) patterns of samples were recorded on a Philips X'PERT diffractometer using $\mathrm{CuK} \alpha$ radiation with a Nickel filter. The crystal morphology was studied by scanning electron microscopy (SEM) using a Hitachi TM-1000 tabletop microscope. Elemental analyses were performed by inductively coupled plasma optical emission spectrometry (ICP-OES, Perkin-Elmer 3300DV instrument) after sample dissolution by alkaline fusion. ${ }^{31} \mathrm{P}$ MAS NMR spectra were recorded at room temperature using a Bruker AV-400-WB spectrometer with a $4 \mathrm{~mm}$ probe spinning at $10 \mathrm{kHz}$, using a $\pi / 6$ pulse of $2 \mu \mathrm{s}$, contact time of 3 $\mathrm{ms}$ and recycle delay of $20 \mathrm{~s}$. The spectra were recorded while spinning the samples at $162 \mathrm{MHz}$. For transmission electron microscopy analysis (TEM) the material was carefully dispersed in ethanol and a drop of the suspension was placed onto a holey carbon copper microgrid. TEM observations were performed in field emission JEOL-2100F microscope operated at $200 \mathrm{kV}$, equipped with a Gatan CCD camera and an Oxford systems EDS detector for chemical analysis.

The content (in weight\%) of HAp in the materials is calculated from the content in $\mathrm{P}$ obtained from the elemental analysis (weight\% P (ICP)), according to eqn (1):

$$
\text { HAp } w t \%=P_{(\text {ICP })} w t \% \times \frac{502}{93}
$$

where 502 is the total molecular mass of HAp, and 93 is the molecular mass of $\mathrm{P}$ in HAp $\left(\mathrm{Ca}_{5}\left(\mathrm{PO}_{4}\right)_{3} \mathrm{OH}\right)$.

Defluoridation was carried out at room temperature, with a contact time of $20 \mathrm{~h}$ under continuous agitation. The concentration of fluoride in the initial solution and after equilibrium upon the addition of the adsorbent was measured by the ion selective electrode technique with a pH\&Ion-meter GLP 22 CRYSON; TISAB III (CRYSON) was used as buffer.

The intrinsic capacity of HAp $\left(C_{\mathrm{HAp}}\right)$ referred only to the percentage of HAp (eqn (1)) in the composite material, and was calculated following eqn (2):

$$
C_{\mathrm{HAp}}=\frac{[F]_{\mathrm{o}}-[F]_{\mathrm{f}}}{\text { total dose } \times \frac{\left(\mathrm{wt}^{\%} \% \mathrm{HAp}\right)}{100}}
$$

where $[F]_{\mathrm{o}}$ and $[F]_{\mathrm{f}}$ refer to the initial fluoride concentration and to the concentration after the elimination process, respectively, and are given in $\mathrm{mg} \mathrm{L}^{-1}$. The total dose corresponds to the mass of the composite, including zeolite and HAp, per volume of solution to be treated (in $\mathrm{g} \mathrm{L}^{-1}$ ), and (wt\% HAp) accounts for the weight percentage of HAp in the composite material, calculated following eqn (1). Capacities are given in $\mathrm{mg}$ of $\mathrm{F}^{-}$per gram of HAp.

\section{Conclusions}

Our work reports a method to carefully control the crystal size of nano-hydroxyapatite by crystallisation on the surface of the natural zeolite stilbite by means of a cationic ion-exchange and subsequent crystallisation through regulation of the crystallisation temperature and time. Room temperature and relatively short times $(19 \mathrm{~h})$ allow for the production of very small nanosized hydroxyapatite crystals that have a very high fluorideremoval capacity. The optimized STI/nHAp is capable of working under very demanding conditions, in solutions with $5.0 \mathrm{mg} \mathrm{L}^{-1}$ of fluoride initial concentrations, at $\mathrm{pH}$ values similar to those of real waters, reducing to the WHO limit with a dose of $0.5 \mathrm{~g}$ of HAp per litre. The low cost and easy accessibility of the materials employed for the preparation of this composite, the simplicity of the synthesis procedure, and the attachment of the nanosized crystals to the zeolite surface with the potential reduction of pressure drops caused by nano-hydroxyapatite, make these materials suitable candidates for their use on fluoride removal from drinking waters.

\section{Acknowledgements}

Dr Asfawossen Asrat and Prof. Solomon Tadesse, Earth Sciences Department, Addis Ababa University, are deeply acknowledged for providing the natural zeolite samples. The authors gratefully acknowledge the financial support from the Spanish Ministry of Foreign Affairs-AECID through the Scientific Cooperation Program (A1/035517/11), and Spanish National Research Council (CSIC) I-COOP- $\mathrm{H}_{2} \mathrm{O}$ (2013CD0009). L.G.H. acknowledges the Spanish Ministry of Economy and Competitiveness for a Juan de la Cierva contract. I. Díaz acknowledges CSIC for permission of research leave at AAU, Ethiopia.

\section{Notes and references}

1 J. Fawell, K. Bailey, E. Chilton, E. Dahi, L. Fewtrell and Y. Magara, Fluoride in Drinking Water, World Health Organization, IWA Publishing, UK, 2006.

2 World Health Organization, Guidelines for Drinking-water Quality. Health Criteria and Other Supporting Information, World Health Organization, Geneva, 2nd edn, 1996, vol. 2.

3 S. Jagtap, M. K. Yenkie, N. Labhsetwar and S. Rayalu, Chem. Rev., 2012, 112, 2454-2466. 
4 P. Loganathan, S. Vigneswaran, J. Kandasamy and R. Naidu, J. Hazard. Mater., 2013, 1-19, 248-249.

5 G. L. He and S. R. Cao, Fluoride, 1996, 29, 212-216.

6 V. E. Badillo-Almaraz, J. Armando-Flores, H. Arriola, F. A. López and L. Ruiz-Ramirez, J. Radioanal. Nucl. Chem., 2007, 271, 741-744.

7 C. Sundaram, N. Viswanathan and S. Meenakshi, Bioresour. Technol., 2008, 99, 8226-8230.

8 S. Gao, J. Cui and Z. Wei, J. Fluorine Chem., 2009, 130, 10351041.

9 M. Jiménez-Reyes and M. Solache-Ríos, J. Hazard. Mater., 2010, 180, 297-302.

10 W. Liang, L. Zhan, L. Piao and C. Russel, Mater. Res. Bull., 2011, 46, 205-209.

11 M. Mourabet, A. El Rhilassi, H. El Boujaady, M. BennaniZiatni, R. El Hamri and A. Taitai, Appl. Surf. Sci., 2012, 258, 4402-4410.

12 D. Zang, H. Luo, L. Zheng, K. Wang, H. Li, Y. Wang and H. Feng, J. Hazard. Mater., 2012, 241-242, 418-426.

13 C. Sundaram, N. Viswanathan and S. Meenakshi, J. Hazard. Mater., 2008, 155, 206-215.

14 S. Gao, R. Sun, Z. Wei, H. Zhao, H. Li and F. Hu, J. Fluorine Chem., 2009, 130, 550-556.

15 G. E. J. Poinern, M. K. Ghosh, Y.-J. Ng, T. B. Issa, S. Anand and P. Singh, J. Hazard. Mater., 2011, 185, 29-37.

16 C. Sundaram, N. Viswanathan and S. Meenakshi, J. Hazard. Mater., 2009, 172, 147-151.

17 L. Gómez-Hortigüela, J. Pérez-Pariente, R. García, Y. Chebude and I. Díaz, Sep. Purif. Technol., 2013, 120, 224-229.
18 P. Van Straaten, Ethiopia, in Rocks for Crops: Agromi-nerals of Sub-Saharan Africa, ICRAF, Nairobi, Kenya, 2002, pp. 137144, ISBN 0889555125, 9780889555129.

19 Report on Exploration and Evaluation of Zeolite at Hawassa Area, SNNP Regional State by M. Tigistu, T. Negash and L. Kassa Addis Ababa, Ethiopia, July 2010.

20 I. Díaz, Y. Chebude, R. García, L. Gómez-Hortigüela, J. PérezPariente, A. Asrat, S. Tadesse and A. B. Pinar, Proceedings of the 17th International Zeolite Conference, 2013, vol. B (Part 1), pp. 226-227.

21 L. Gómez-Hortigüela, J. Pérez Pariente, I. Díaz Carretero and Y. Chebude, Patent aplication number P 201330262, CSICAddis Ababa University, 26 February, 2013.

22 L. Gómez-Hortigüela, A. B. Pinar, J. Pérez-Pariente, Y. Chebude and I. Díaz, Microporous Mesoporous Mater., submitted.

23 Y. Watanabe, Y. Moriyoshi, Y. Suetsugu, T. Ikoma, T. Kasama, T. Hashimoto, H. Yamada and J. Tanaka, J. Am. Ceram. Soc., 2004, 87, 1395-1397.

24 Y. Watanabe, T. Ikoma, Y. Suetsugu, H. Yamada, K. Tamura, Y. Komatsu, J. Tanaka and Y. Moriyoshi, J. Eur. Ceram. Soc., 2006, 26, 469-474.

25 C. Baerlocher, L. B. McCusker and D. H. Olson, Atlas of Zeolite Framework Types, Elsevier, Amsterdam, 2007.

26 T. W. T. Tsai and J. C. C. Chan, Annual Reports on NMR spectroscopy, Recent Progress in the Solid-State NMR Studies of Biomineralization, 2011, vol. 73, ch. 1.

27 C. Jäger, T. Welzel, W. Meyer-Zaika and M. Epple, Magn. Reson. Chem., 2006, 44, 573-580. 